\title{
Respiratory, allergy and eye problems in bagasse-exposed sugar cane workers in Costa Rica
}

\author{
Mireia Gascon, ${ }^{1,2}$ Hans Kromhout, ${ }^{2}$ Dick Heederik, ${ }^{2}$ Wijnand Eduard, ${ }^{3}$ \\ Berna van Wendel de Joode ${ }^{1}$
}

${ }^{1}$ Programa Salud y Trabajo en América Central (SALTRA), Central American Institute for Studies on Toxic Substances (IRET), Universidad Nacional de Costa Rica (UNA), Heredia, Costa Rica

${ }^{2}$ Division of Environmental Epidemiology, Institute for Risk Assessment Sciences (IRAS), Utrecht University (UU), Utrecht, The Netherlands ${ }^{3}$ Department of Chemical and Biological Work Environment, National Institute of Occupational Health (STAMI). Oslo, Norway

\section{Correspondence to}

Dr Berna van Wendel de Joode, Programa Salud y Trabajo en América Central (SALTRA), Central American Institute for Studies on Toxic Substances (IRET), Universidad Nacional de Costa Rica (UNA), Apdo, Heredia 86-3000, Costa Rica; bvanwen@una.ac.cr

Accepted 30 August 2011 Published Online First 22 January 2012

\begin{abstract}
Aims To evaluate bagasse (sugar cane fibres) and microbiological exposure among sugar cane refinery workers in Costa Rica and its relationships with respiratory, allergy and eye problems.
\end{abstract}

Methods Ventilatory lung function and total serum lgE were measured in 104 sugar cane workers in five departments at one refinery before the harvesting season, and repeated for 77 of the workers at the end of the season. Information on the prevalence of respiratory and other symptoms was collected with a standardised questionnaire. During the harvesting season, inhalable dust, endotoxin and mould levels were measured among 74 randomly selected sugar cane workers across departments

Results During the harvesting season, dust levels were relatively high in some departments, while endotoxin and mould levels were around background levels. Workers' ventilatory lung function differed between departments before, but not during the harvesting season or between seasons. During the harvesting season, the prevalence of wheeze and eye problems almost doubled in workers exposed to bagasse and other types of dust, whereas shortness of breath and rhinitis increased only in bagasse-exposed workers. Reporting wheeze and shortness of breath was positively associated with the number of years working at the refinery, suggesting a long-term health effect.

Conclusion In this refinery, the differences in workers' ventilatory lung function before the harvesting season are unlikely to be explained by bagasse exposure. However, the increase in reported symptoms (wheeze, shortness of breath, eye problems and rhinitis) over the season is likely due to irritation by dust, in particular bagasse, rather than microbiological agents.

\section{INTRODUCTION}

The production of sugar cane in Costa Rica is an important economic activity with over 56000 hectares $(1.10 \%$ of the land surface of Costa Rica) planted with sugar cane. One of the most productive regions is Guanacaste, which produces half of the total harvest. Sugar cane production is currently rising as a result of the increased demand for biofuels. 12

Harvesting occurs between mid-December and the end of April (dry season). During this period, sugar cane is processed into sugar, ethanol and honey, and workers are potentially exposed to high levels of dust, consisting mainly of bagasse (sugar cane fibres). Most of the bagasse is used after juice

\section{What this paper adds}

- The few studies carried out on sugar cane workers' respiratory health lack quantitative exposure evaluations.

- Our results suggest bagasse exposure may cause short- and long-term respiratory health problems as workers more frequently reported wheeze and shortness of breath during than before the harvesting season.

- Bagasse exposure did not seem to affect the ventilatory lung function parameters forced expiratory volume in $1 \mathrm{~s}\left(\mathrm{FEV}_{1}\right)$, forced vital capacity (FVC) and $\mathrm{FEV}_{1} / \mathrm{FVC}$.

- The increase in reported symptoms over the season is likely due to irritation by dust, in particular bagasse, rather than microbiological agents.

- We recommend reducing workers' exposure to bagasse dust by enclosing the production process.

extraction to generate energy for the sugar processing plant. Some of the harvest is kept until the next season to start up the factory. Apart from being an energy source, bagasse is also used, for example, for the production of paper and disposable food containers, or as food for cattle. Bagasse can be contaminated with high levels of bacteria and moulds such as Thermophilic actinomycetes (ie, Thermoactinomyces vulgaris and Thermoactinomyces sacchari $i^{3}$ ) especially during the rainy season after being stored for months. As in other organic dusts, microbiological agents such as endotoxins can also be present; detected levels in other agricultural sectors were between 1.6 and $190000 \mathrm{EU} / \mathrm{m}^{3}$. Exposures to dust and microbiological agents have, in general, been associated with respiratory, allergy and eye problems. ${ }^{5-9}$ It is well known that exposure to endotoxin can induce non-atopic asthma, even at low levels, while the same exposure can also protect against atopic disease and the development of hay fever. $^{6} 7$ 10-12 Fungi are also suspected to cause allergic and non-allergic inflammatory reactions. ${ }^{13}$

So far, few studies have examined the respiratory and immunological effects of exposure to bagasse and its biocontaminants. ${ }^{14-17}$ One of the most deleterious effects reported in sugar cane workers is bagassosis, an extrinsic allergic alveolitis resulting from the inhalation of high concentrations of 
bagasse contaminated with actinomycetes. ${ }^{8} 18$ The disease has distinct acute and chronic stages. ${ }^{16} 1920$ Bagasse exposure has also been associated with ocular irritation and a higher probability of eye infections. ${ }^{5} 21$

Studies including quantitative exposure assessment and measurement of health effects in sugar cane workers are generally restricted to tropical countries. ${ }^{14-17}$ These studies also have limitations: exposure assessment was not always based on personal sampling ${ }^{15} 16$ and workers were not always classified according to their exposure but according to their respiratory symptoms ${ }^{14}$ or the presence of precipitins against $T$ vulgaris or Tsacchari. ${ }^{17}$

The aim of the present study was to explore personal exposure to dust, bagasse and its biocontaminants (thermophilic actinomycetes and microbiological agents) among workers in a sugar refinery in Costa Rica and to evaluate its associations with respiratory, allergy and eye problems.

\section{MATERIALS AND METHODS Design}

This longitudinal study with 3 months of follow-up was conducted with the participation of voluntary male workers in a sugar cane company in Guanacaste province in Costa Rica. The study started 1 month before the harvesting season (November 2008) and finished towards the end of the season (March 2009). The study was approved by the ethics committee of the Universidad Nacional (UNA) in Costa Rica (approval CEC-UNA-021-2008). Workers were informed about the study and all $(n=104)$ voluntarily agreed to participate in the noninvasive section. A total of 64 workers donated a blood sample at the start and towards the end of the study. All participants signed a written informed consent.

\section{Sugar cane processing}

In this refinery, canes are first cleaned with water and cut. The canes are then milled in the mill department and a dithiocarbamate is added to prevent the growth of Leuconostoc mesenteroides. After juice extraction, waste bagasse is transported to the boiler department were it is burned as an energy source for the production process. In the crystallisation department, the juice is processed to produce sugar and other products. In the lathe department, next to the boiler and mill departments, pieces and tools are repaired. Vehicles and electronic devices are repaired in the maintenance department, which is $1 \mathrm{~km}$ away from the refinery.

\section{Study population}

In collaboration with the company's occupational hygienist, workers $(n=104)$ from five departments were randomly selected based on their expected differing levels of exposure to bagasse: (1) boiler department (high expected exposure; $n=28$ ); (2) mill department (medium-high expected exposure; $n=16$ ); (3) lathe department (medium-low expected exposure; $n=8$ ); (4) crystallisation department (low expected exposure; $n=18$ ); and (5) maintenance department (low expected exposure; $n=34$ ).

\section{Exposure assessment}

Personal dust levels and their biological constituents were measured for 5 weeks during the harvesting season (from midFebruary to mid-March). Randomly selected workers $(n=74)$ from the five departments participated. Portable pumps (GilAir-5, 21/min flow; Sysmex Nederland BV, Etten Leur, The Netherlands) with PAS6 sampling heads containing glass-fibre filters (Whatman GF/A, 25 mm; Whatman, Maidstone, Kent, UK), were used to measure inhalable dust. Workers carried pumps for 7-8 $\mathrm{h}$ with the sampling heads positioned in their breathing zone. Filters were weighed before and after sampling with an analytical balance. Two blanks per sampling day were used. After sampling, filters were stored in $10 \mathrm{ml}$ tubes containing $0.05 \%$ Tween 20 in $5 \mathrm{ml}$ pyrogen-free water and stored at $-20^{\circ} \mathrm{C}$ until shipment. Samples were transported to the Netherlands at $4^{\circ} \mathrm{C}$, extracted and analysed. For endotoxin extraction, tubes were shaken vigorously for $1 \mathrm{~h}$ at room temperature. After $15 \mathrm{~min}$ of centrifugation at $2000 \mathrm{rpm}$, the supernatant was removed and stored in five $0.1 \mathrm{ml}$ tubes. Endotoxin concentrations were assayed using a quantitative kinetic chromogenic Limulus amoebocyte lysate (LAL) method (BioWhittaker, Lonza, Verviers, Belgium). ${ }^{22}$ All calibration lines were parallel, suggesting that no interaction or enhancement had occurred.

Personal mould samples were taken for six workers from the boiler $(n=2)$, mill $(n=2)$ and crystallisation $(n=2)$ departments on the same day. One blank sample was taken. The same pumps and sampling heads were used as for inhalable dust, but using polycarbonate filters (pore size $0.8 \mu \mathrm{m}, 25 \mathrm{~mm}$ diameter; Poretics, Minnetonka, Minnesota, USA). After sampling, filters were kept in $25 \mathrm{~mm}$ diameter cassettes in a box with silica gel and sent to the National Institute of Occupational Health, Oslo, Norway for further analysis. Specimens of approximately $10 \times 10 \mathrm{~mm}$ were cut from the filters, mounted with carbon tabs on carbon stubs $(15 \mathrm{~mm})$ and coated with platinum under vacuum (0.4 mbar) using a Bal-Tec SCD 050 sputter coater (BalTec, Balzers, Principality of Liechtenstein). The specimens were examined with a Jeol JSM-6400 microscope (Jeol, Tokyo, Japan) operated at $15 \mathrm{keV}$ at $12205 \mathrm{I}$. In each sample, spores were counted in 100 fields at $3000 \times$ magnification. A size cut-off of $1.5 \mu \mathrm{m}$ diameter was used to separate fungal spores from actinomycete spores. Spore concentrations were calculated from the number of spores counted, the area observed by scanning electron microscope and the area of the exposed filter. The minimal countable number of spores was one, equal to $<5000$ spores per filter.

Workers were asked about activities performed in their departments, and on sampling days, information on workers' activities was collected as well.

\section{Health outcomes}

Before the harvesting season (November-December 2008), one of the researchers (MGM) conducted a questionnaire survey among workers based on the European Community Respiratory Health Survey II. ${ }^{23}$ Workers were asked about respiratory and other symptoms (wheeze, shortness of breath (SOB), chronic cough and asthma, rhinitis, allergy and eye problems) during the last 12 months and the last 3 months (non-harvesting season). Towards the end of the harvesting season (March 2009), the same researcher re-conducted part of the same questionnaire and workers were asked about symptoms during the last 3 months, covering the current harvesting season only. Wheeze was defined as the occurrence of whistling sounds in the chest without having a cold or the flu. SOB was considered to be present if the participant had reported $\mathrm{SOB}$ during the day while resting or following light activity or at night while sleeping. Rhinitis was defined as the occurrence of nasal symptoms, such as sneezing, runny nose or nasal itching without having a cold or the flu. Eye problems were considered to be present if the participant had reported any of irritation, itch, infections, secretions, dry eyes, wet eyes or particles in the eyes.

The same researcher evaluated workers' ventilatory capacity using a MIR Spirotel spirometer (Medical International 
Research, Rome, Italy), before $(\mathrm{N}=104)$ and towards the end of the harvesting season $(\mathrm{N}=76)$. Both forced vital capacity (FVC) and forced expiratory volume in $1 \mathrm{~s}\left(\mathrm{FEV}_{1}\right)$ were measured. In order to ensure good quality results, the most recent guidelines ${ }^{24}$ were followed for the use of a nose clip, explanation from the researcher to each worker on how to perform the test correctly (correct posture, how to inhale and exhale, position of the mouth piece, etc) and coaching by the researcher during the test. A minimum of three and a maximum of eight tests were performed during the day (from 7:00 h till 18:00 h) in the first aid department. A bronchodilator was not used. The curves of the tests were analysed with Winspiro 2.42 c software. Predicted values were calculated according to reference equations obtained from the third National Health and Nutrition Estimation Survey (NHANES III). ${ }^{25}$ The equations for Mexican American males over 20 years of age were used, since this was the closest reference population available. For the analyses of the lung function tests, we also evaluated the influence of the time at which lung function tests were performed.

Blood samples were taken at the start and towards the end of the harvesting season. Samples were centrifuged at $1000 \mathrm{rpm}$ for $10 \mathrm{~min}$ and the serum transferred to $1.5 \mathrm{ml}$ Eppendorf tubes to be frozen and transported to the Netherlands for analysis. Total IgE as well as specific IgE for five common aeroallergens (house dust mite, grass pollen, birch pollen, cat dander and dog dander) were determined in all serum samples as described by Doekes et $a$. $^{26}$ Workers were considered atopic if specific IgE to at least one allergen was detected, either before or during the harvesting season.

\section{Data analysis}

\section{Exposure assessment}

The limit of detection (LOD) for inhalable dust was $0.35 \mathrm{mg}$. LODs for endotoxin samples were 0.012-0.014 EU/filter. For samples with levels below the LOD, a random value was assigned as described by Lubin et al. ${ }^{27}$ Dust and endotoxin concentrations followed a log-normal distribution and were logtransformed before statistical analysis. Statistical analyses were performed with SAS V.9.1.

The between department $\left(\mathrm{SS}_{\mathrm{BG}}\right)$, between worker $\left(\mathrm{SS}_{\mathrm{WG}}\right)$ and day-to-day $\left(\mathrm{SS}_{\mathrm{WW}}\right)$ variability were estimated using a mixed model analysis procedure. Contrast in exposure was assessed by the ratio of the between group variance and the sum of the between group and within group variance (SS $\mathrm{SG}_{\mathrm{BG}}$ $\left.\left(\mathrm{SS}_{\mathrm{BG}}+\mathrm{SS}_{\mathrm{WG}}\right)\right)^{28}$ So that there would be enough statistical power and to ensure the maximum contrast in exposure between analysis groups, workers were re-classified into three groups: 'bagasse group' (boiler and mill departments), 'other dust group' (lathe and maintenance departments) and 'reference group' (crystallisation department). All workers normally carried out the same tasks within each department; if there was any change, it was within each department and not between departments. Given the diversity of tasks and the small number of workers per task, it was impossible to carry out analysis at task level.

\section{Health outcomes}

To evaluate the effects of long-term exposure on health, a crosssectional analysis was performed for the symptoms reported by workers during the last 12 months before the harvesting period $(\mathrm{N}=104)$. Linear regression analysis was used to explore associations between FVC, $\mathrm{FEV}_{1}$ and total $\operatorname{IgE}$ and exposure, after adjustment for confounders. Levels of total IgE were log-transformed before analysis. Logistic regression modelling was used to estimate ORs for atopic status and self-reported health problems comparing different exposure groups. Confounders were included in the final models if their significance was $\mathrm{p}<0.10$ and/ or if there was a change in the estimated effect of more than $10 \%$ for any of the health outcomes. The tested covariables were: age, height, body mass index (BMI), smoking (current smokers/workers who had stopped smoking less than 1 year previously, ex-smokers), smoking pack years, nationality, education (illiterate, primary or secondary school, university), being a temporary worker (only working during the harvesting season), years working in the company, task within each department, type of house (own house, company cabin, other), cooking system usually used at home (electric, butane, wood, other), having the kitchen inside or outside the house, having pets at home and moulds at home. For the analyses of the lung function tests, we also evaluated the influence of the time of day that the tests were performed. To evaluate the effects of shortterm exposure, symptoms reported by workers during the last 3 months before the harvesting season were compared with symptoms reported towards the end of the harvesting season $(\mathrm{N}=77)$. Differences between seasons were analysed with the paired t test (continuous variables) or McNemar's test (binary outcomes).

\section{RESULTS}

\section{Exposure to dust and endotoxins}

During the sampling period, the average temperature was $30^{\circ} \mathrm{C}$ (range $26^{\circ} \mathrm{C}-31^{\circ} \mathrm{C}$ ) and humidity was $49 \%$ (range $39 \%-65 \%$ ), according to the meteorological data provided by the sugar cane company. A total of 108 valid samples from 74 workers were collected. Sixteen (14.8\%) dust and 12 (11.1\%) endotoxin samples were below the LOD.

Table 1 shows the personal inhalable dust and endotoxin levels measured for each department. The highest dust levels were measured in the maintenance department (geometric mean $2.72 \mathrm{mg} / \mathrm{m}^{3}$ ). In the boiler, mill and lathe departments, dust levels were similar, and approximately $2-3$ times higher than in the crystallisation department (geometric mean 1.06, 0.80 and 0.77 vs $0.35 \mathrm{mg} / \mathrm{m}^{3}$, respectively; $\mathrm{p}<0.05$ ). Visual inspection of filters showed that the type of dust differed between departments. For workers in the boiler and mill departments, dust consisted of bagasse fibres and ashes (from the boilers), whereas in the lathe and maintenance departments dust consisted of sand and welding fumes. Endotoxin levels were higher for the boiler and mill departments (geometric mean 2.38 and $3.49 \mathrm{EU} /$ mg dust, respectively) as compared to the lathe and maintenance departments (geometric mean 1.34 and $1.22 \mathrm{EU} / \mathrm{mg}$ dust, respectively; $p<0.05)$. For the crystallisation department, endotoxin concentrations were also relatively high (geometric mean $2.84 \mathrm{EU} / \mathrm{mg}$ dust). However, this was due to the low dust levels measured (geometric mean $0.35 \mathrm{mg} / \mathrm{m}^{3}$ ). Inhalable dust and

Table 1 Personal inhalable dust and endotoxin levels and concentrations for each department

\begin{tabular}{lllll}
\hline Department & $\mathbf{N}(\mathbf{n})$ & $\begin{array}{l}\text { Dust }\left(\mathbf{m g} / \mathbf{m}^{\mathbf{3}}\right), \\
\text { GM (GSD) }\end{array}$ & $\begin{array}{l}\text { Endotoxin }\left(\mathrm{EU} / \mathbf{m}^{\mathbf{3}}\right), \\
\text { GM (GSD) }\end{array}$ & $\begin{array}{l}\text { Endotoxin (EU/mg } \\
\text { dust), GM (GSD) }\end{array}$ \\
\hline Boiler & $30(24)$ & $1.06(3.02)$ & $2.52(2.04)$ & $2.38(2.81)$ \\
Mill & $18(11)$ & $0.80(2.96)$ & $2.80(3.29)$ & $3.49(4.03)$ \\
Lathe & $16(10)$ & $0.77(2.79)$ & $1.04(1.76)$ & $1.34(2.95)$ \\
Crystallisation & $21(15)$ & $0.35(2.00)$ & $1.00(2.12)$ & $2.84(2.14)$ \\
Maintenance & $23(14)$ & $2.72(4.17)$ & $3.33(3.66)$ & $1.22(2.15)$ \\
\hline
\end{tabular}

$\mathrm{GM}$, geometric mean; GSD, geometric $\mathrm{SD} ; \mathrm{N}$, number of samples; $\mathrm{n}$, number of workers. 
Table 2 Estimated variance components between groups $\left(\mathrm{SS}_{\mathrm{BG}}\right)$, between workers $\left(\mathrm{SS}_{\mathrm{WG}}\right)$ and within workers $\left(\mathrm{SS}_{\mathrm{Ww}}\right)$ or day-to-day for the 108 measurements of dust $\left(\mathrm{mg} / \mathrm{m}^{3}\right)$ and endotoxin $\left(\mathrm{EU} / \mathrm{m}^{3}\right.$ and EU/ $\mathrm{mg}$ dust) in 74 workers

\begin{tabular}{|c|c|c|c|c|c|}
\hline Exposure & Group & $\begin{array}{l}\text { Between } \\
\left.\text { groups (SS }{ }_{\mathrm{BG}}\right)\end{array}$ & $\begin{array}{l}\text { Between } \\
\left.\text { workers (SS }{ }_{\text {WG }}\right)\end{array}$ & $\begin{array}{l}\text { Day-to-day } \\
\left.\text { (SS } S_{w w}\right)\end{array}$ & $\begin{array}{l}\text { Contrast }\left(\mathrm{SS}_{\mathrm{BG}} /\right. \\
\left.\left(\mathrm{SS}_{\mathrm{BG}}+\mathrm{SS}_{\mathrm{WG}}\right)\right)\end{array}$ \\
\hline \multirow[t]{3}{*}{ Dust $\left(\mathrm{mg} / \mathrm{m}^{3}\right)$} & Bagasse group & 0.58 & 0.11 & 1.07 & 0.84 \\
\hline & Other dust group & & & 1.85 & \\
\hline & Reference group & & & 0.38 & \\
\hline \multirow[t]{3}{*}{ Endotoxin $\left(E U / \mathrm{m}^{3}\right)$} & Bagasse group & 0.24 & 0.26 & 0.60 & 0.48 \\
\hline & Other dust group & & & 1.14 & \\
\hline & Reference group & & & 0.26 & \\
\hline \multirow[t]{3}{*}{ Endotoxin (EU/mg dust) } & Bagasse group & 0.18 & 0.13 & 1.29 & 0.58 \\
\hline & Other dust group & & & 0.68 & \\
\hline & Reference group & & & 0.4 & \\
\hline
\end{tabular}

Within each group, the within-worker variability was larger than the between-worker variability, indicating that exposure levels

fluctuated considerably from day to day between workers from the same exposure group.

endotoxin levels were moderately correlated (Pearson's $r=0.70$, $\mathrm{p}<0.001)$.

After regrouping the departments into three exposure groups, the contrast for inhalable dust and endotoxin exposure was 0.84 and 0.48 , respectively (table 2 ).

Exposure to fungal spores was very low (results not presented). The number of spores was too low to estimate concentrations, with a maximum count of three. Only one actinomycete spore was observed, but outside the region observed for counting.

\section{Health outcomes}

Characteristics of the study population

Table 3 shows that age, BMI and years working in the company were similar for the three groups. In all departments, subjects had a BMI over 25.0, suggesting general obesity. In the other dust group, the percentage of smokers (47.6\%) was twice as high as compared to the bagasse group $(27.3 \%)$ and the reference group $(22.2 \%)$, with borderline significant differences $(p=0.08)$. Somewhat more Nicaraguans were present in the bagasse group as compared to the other groups $(22.7 \%$ vs $14.3 \%$ and $16.7 \%$, respectively), but differences were not statistically significant. Nevertheless, being Nicaraguan was significantly associated with being a temporary worker $(p<0.001)$ and type of housing $(\mathrm{p}=0.002)$.

\section{Long-term effects}

Workers in the different exposure groups showed similar FEV 1 and FVC values. However, $\mathrm{FEV}_{1} / \mathrm{FVC}$ ratios differed somewhat, in particular before the harvesting season started. Before the harvesting season, after adjusting for age, height and smoking, workers in the bagasse group tended to have a lower $\mathrm{FEV}_{1} / \mathrm{FVC}$

Table 3 Characteristics of the 104 sugar cane refinery workers specified for each exposure group

\begin{tabular}{llll}
\hline All workers $(\mathbf{n}=\mathbf{1 0 4})$ & Bagasse group $(\mathbf{n}=\mathbf{4 4 )}$ & 0ther dust group $(\mathbf{n}=\mathbf{4 2})$ & Reference group $(\mathbf{n}=\mathbf{1 8})$ \\
\hline Age (years) & $36.8(11.2)$ & $39.3(10.9)$ & $35.9(12.6)$ \\
BMI before harvesting & $27.3(4.0)$ & $27.2(5.1)$ & $27.9(4.8)$
\end{tabular}
season $\left(\mathrm{kg} / \mathrm{m}^{2}\right)$

$\begin{array}{lll}\text { Years working in the company } & 8.7(7.5) & 8.0(9.5)\end{array}$

\begin{tabular}{|c|c|c|c|}
\hline & $\mathrm{n}(\%)$ & $\mathrm{n}(\%)$ & $\mathrm{n}(\%)$ \\
\hline Smoking* & $12(27.3)$ & $20(47.6)$ & $4(22.2)$ \\
\hline Temporary workers & $17(38.6)$ & $6(14.3)$ & $7(38.9)$ \\
\hline Nicaraguans & $10(22.7)$ & $6(14.3)$ & $3(16.7)$ \\
\hline Lost to follow-up & $9(20.5)$ & $15(35.7)$ & $3(16.7)$ \\
\hline $\begin{array}{l}\text { Only workers with results for } \\
\text { both periods }(n=76)\end{array}$ & Bagasse group $(n=35)$ & Other dust group $(n=26)$ & Reference group $(n=15)$ \\
\hline FVC (I) before HS & $4.43(0.59)$ & $4.35(0.76)$ & $4.41(1.05)$ \\
\hline FVC (I) during HS & $4.33(0.62)$ & $4.27(0.76)$ & $4.46(1.09)$ \\
\hline $\mathrm{FEV}_{1}$ (I) before HS & $3.83(0.53)$ & $3.61(0.61)$ & $3.91(0.91)$ \\
\hline FVC (I) during HS & $3.73(0.58)$ & $3.60(0.58)$ & $3.89(0.89)$ \\
\hline $\mathrm{FEV}_{1} / \mathrm{FVC}(\%)$ before $\mathrm{HS}$ & $86.6(5.9) \dagger$ & $83.3(5.2) \neq$ & $89.1(6.9)$ \\
\hline $\mathrm{FEV}_{1} / \mathrm{FVC}(\%)$ during $\mathrm{HS}$ & $86.0(5.8) \S$ & $84.7(6.2) \Phi$ & $87.9(7.3)$ \\
\hline $\begin{array}{l}\text { Predicted vs observed } \mathrm{FEV}_{1} / \\
\text { FVC values (\%) before HS }\end{array}$ & $105.8(6.2)$ & $102.1(6.2)$ & $108.8(9.9)$ \\
\hline $\begin{array}{l}\text { Predicted vs observed } \mathrm{FEV}_{1} / \\
\text { FVC values (\%) during HS }\end{array}$ & $105.1(5.9)$ & $103.7(8.0)$ & $107.3(10.3)$ \\
\hline
\end{tabular}

Values are mean (SD). Differences between exposed groups and the reference group for $F E V_{1} / F V C$ ratios are only presented for the 76 workers who had complete information for both periods.

*Smoking contains current smokers and workers who stopped smoking less than 1 year previously.

†As compared to the reference group and after adjustment for age, height and smoking, $\beta=-0.03$ (SE 0.02 ), $p=0.09$.

$\ddagger$ As compared to the reference group and after adjustment for age, height and smoking, $\beta=-0.05$ (SE 0.02 ), $p=0.01$.

$\S$ As compared to the reference group and after adjustment for age, height and smoking, $\beta=-0.02$ (SE 0.02), $p=0.23$.

\As compared to the reference group and after adjustment for age, height and smoking, $\beta=-0.03$ (SE 0.02), $p=0.14$.

$\mathrm{BMI}$, body mass index; $\mathrm{FEV}_{1}$, forced expiratory volume in $1 \mathrm{~s}$; FVC, forced ventilatory capacity; HS, harvesting season. 
ratio as compared to the reference group ( $\beta=0.03$ (SE 0.02), $p=0.09)$, whereas for workers in the other dust group, the ratio was significantly lower as compared to the reference group $(\beta=-0.05$ (SE 0.02), $p=0.01$ ) (table 3). All workers had observed $\mathrm{FEV}_{1} / \mathrm{FVC}$ values higher than the predicted values (table 3 ). Although here we only present the results for those 76 workers with complete data on lung function before and during the harvesting season, results were similar for all 104 workers measured before the harvesting season.

Figure 1 shows that the percentage of workers reporting wheezing during the last 12 months before the harvesting season was higher among the workers exposed to bagasse $(20.5 \%)$ or to other types of dust $(16.7 \%)$ than in the reference group $(11.1 \%)$. Workers in the bagasse group reported more SOB $(25 \%)$, followed by the reference group $(11.1 \%)$. However, none of the differences was statistically significant (all $p>0.05$ ). None of the workers reported they had asthma in this first interview. Regarding the analyses in which all workers were included, wheeze was associated with years working in the company (expressed per 10 years) both before (cOR 2.55, 95\% CI 1.45 to 4.49) and after (aOR 2.99, 95\% CI 1.39 to 6.45) adjustment for age and smoking. On the other hand, $\mathrm{SOB}$ was not associated with years working in the company (cOR 1.32, 95\% CI 0.69 to 2.50 and $\mathrm{aOR} 1.54,95 \% \mathrm{CI} 0.88$ to 2.71 , respectively) after adjustment for BMI and smoking.

For lung function tests, a few variables were included in the final models: age, height and smoking.

\section{Short-term effects}

Overall, 26\% of the 104 workers initially enrolled in the study were lost to follow up. The remaining 77 workers with complete data for self-reported symptoms and/or lung function tests consisted of 35 workers in the bagasse group, 27 in the other dust group (including one worker with unacceptable spirometry) and 15 in the reference group. The percentage of participants lost to follow-up was much higher in the other dust group

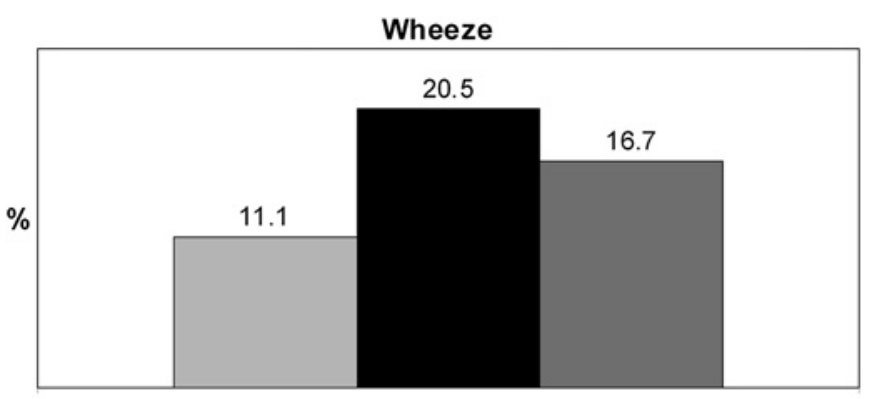

Shortness of breath (SOB)

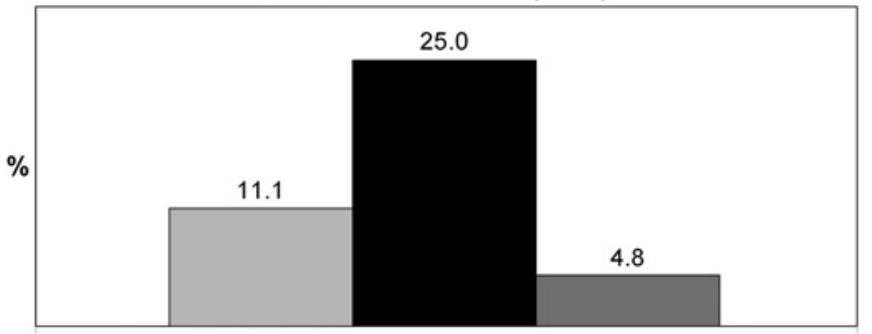

12 months before HS $(n=104)$

$\square$ Reference group $(n=18) \square$ Bagasse group $(n=44) \square$ Other dust group $(n=42)$

Figure 1 Percentage of workers $(n=104)$ reporting wheeze and shortness of breath (SOB) during the 12 months before the harvesting season started. HS, harvesting season.
$(35.7 \%)$ than in the two other groups (around 20\%). All groups in the study population increased in weight during the harvesting season (an average BMI increase of 0.5).

A total of 76 workers had acceptable spirometry tests before and during the harvesting season. One worker from the bagasse group developed asthma during the harvesting season. During the harvesting season differences in the $\mathrm{FEV}_{1} / \mathrm{FVC}$ ratio between exposure groups nearly disappeared (table 3 ). In addition, for each exposure group results were similar before and during the harvesting season (table 3). Also, for each individual, the difference in lung function test results before and during the harvesting season was calculated and entered into the model as the outcome. No significant differences were seen between the reference group and the bagasse group $(\beta=-0.01$ (SE 0.01), $p=0.47$ ) or the other dust group ( $\beta=-0.02$ (SE 0.01), $p=0.13$ ).

Figure 2 shows that the percentage of workers reporting wheeze $(n=76)$ was higher during the harvesting season, in particular among workers from the bagasse group (20.0\%) and the other dust group (15.4\%). Note that in figure 1, where the results of the 104 initial workers are presented, $11.1 \%(\mathrm{~N}=2)$ of the workers in the reference group reported wheeze symptoms during the 12 months before the harvesting season. However, in figure 2, these two workers are not represented because they were lost to follow-up and were not included with the 77 workers with complete data before and during the harvesting season. During the harvesting season, the difference between the bagasse group and the reference group was almost statistically significant $(p=0.06)$. The percentage of workers reporting SOB was also higher during the harvesting season, mainly in the bagasse group (17.1\%), followed by the reference group (13.3\%). The difference between the bagasse group and the other dust group $(3.7 \%)$ was borderline significant $(p=0.06)$. Differences between seasons within exposure groups were not statistically significant for wheeze or SOB.

The percentage of reported eye problems increased in particular for workers from the bagasse group, from $31.4 \%$ before the harvesting season to $77.1 \%$ during harvesting season $(p<0.001)$. Reported eye problems increased among workers from the other dust group from $40.7 \%$ to $70.4 \%(p=0.06)$ and among the reference group from $13.3 \%$ to $33.3 \%(p=0.37)$ (figure 2$)$. During the harvesting season, workers from the bagasse group and the other dust group reported more eye problems than workers from the reference group $(p=0.002$ and $p=0.01$, respectively). The prevalence of rhinitis among bagasse workers increased from $17.1 \%$ to $40 \%$ during the harvesting season $(p=0.04)$, whereas for the reference group and the other dust group there was neither an increase nor a decrease (figure 2).

\section{Total IgE levels and atopy}

Levels of total IgE ranged from $2.65 \mathrm{kU} / 1$ to $5592.5 \mathrm{kU} / 1$ and did not vary between seasons $(p=0.61)$. After adjusting for nationality, smoking, having pets at home and age, only the other dust group showed significantly higher total IgE levels than the reference group for both seasons ( $\beta=1.54$ (SE 0.59), $p=0.01$ and $\beta=1.22$ (SE 0.58), $p=0.04$, respectively). Differences between Nicaraguans (lower levels, data not shown) and Costa Ricans were also significant for both seasons $(p=0.02)$.

The only covariable explaining differences in atopy was nationality. Nicaraguans were less atopic both before and during the harvesting season $(10.5 \%$ and $16.7 \%$, respectively) than Costa Ricans $(35.1 \%$ and $33.3 \%$, respectively) ( $p=0.07$ and $p=0.11$, respectively). The percentage of workers with atopy was similar between groups of exposure within and between seasons (data not shown). 


\section{Wheeze}

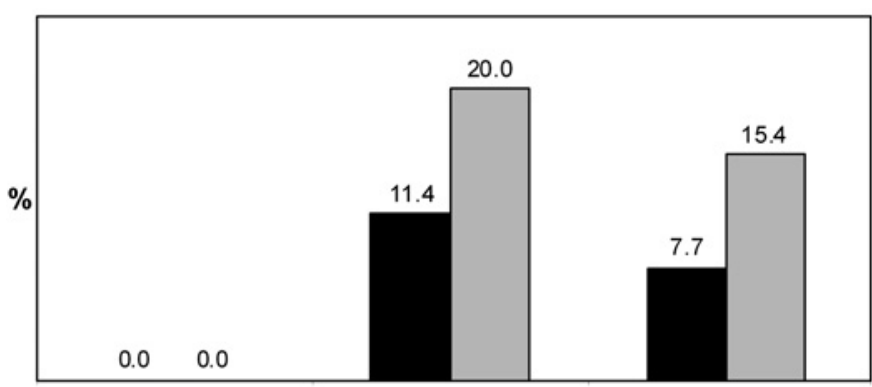

Reference group ( $n=15) \quad$ Bagasse group $(n=35) \quad$ Other dust group ( $n=26)$

3 months before HS $\square$ Harvesting season $(n=76)$

\section{Eye problems}

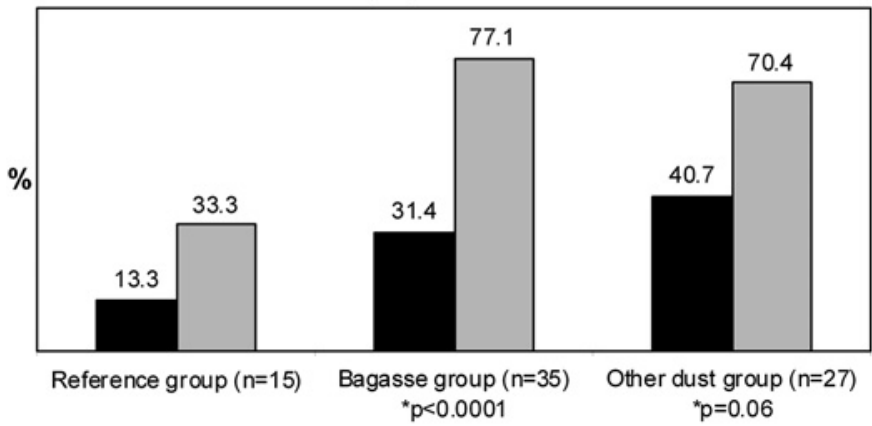

3 months before HS $\square$ Harvesting season $(n=77)$
Shortness of breath (SOB)

17.1

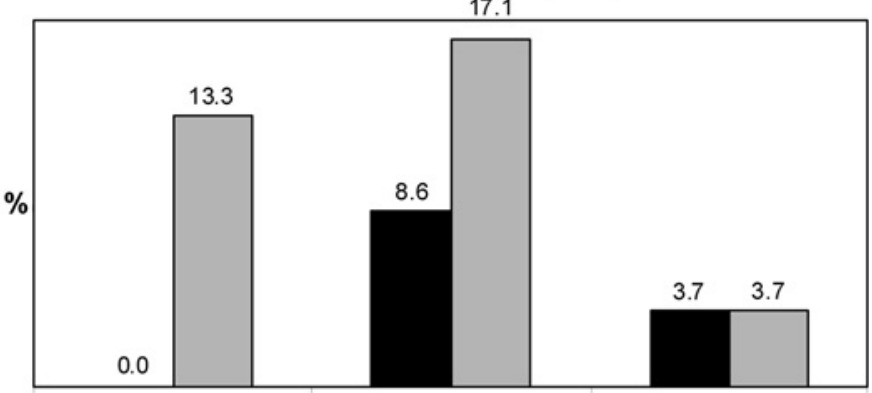

Reference group $(n=15) \quad$ Bagasse group $(n=35) \quad$ Other dust group $(n=27)$

3 months before HS $\square$ Harvesting season $(n=77)$

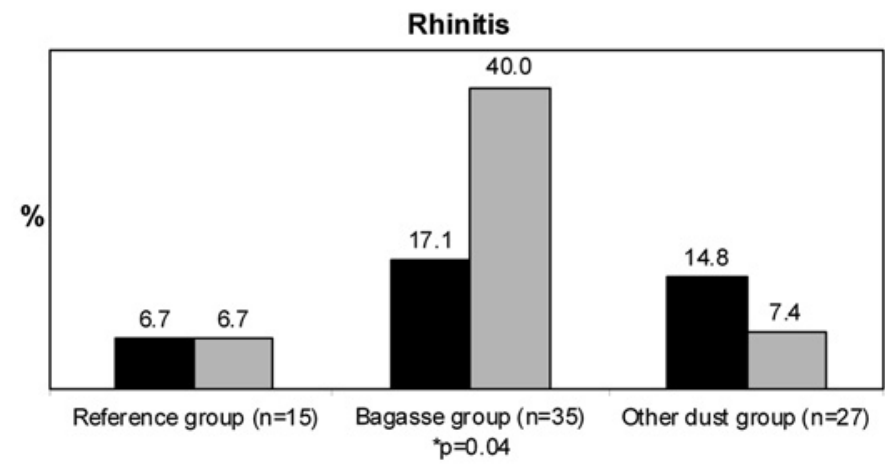

3 months before HS $\square$ Harvesting season $(n=77)$

Figure 2 Percentage of workers reporting wheeze, shortness of breath (SOB), eye problems and rhinitis 3 months before and during the harvesting season (HS) for the 77 workers with complete data at both sampling times (including one worker in the other dust group who did not have information for wheeze 3 months before the harvesting season). * $p$ Values only indicated if $p<0.05$ between seasons within each group.

\section{DISCUSSION}

Our results suggest bagasse exposure may cause short- and longterm respiratory effects as workers more frequently reported wheeze and SOB during the harvesting season as compared to before the harvesting season. Bagasse exposure did not seem to affect the ventilatory lung function parameters $\mathrm{FEV}_{1}, \mathrm{FVC}$ and $\mathrm{FEV}_{1}$ /FVC.

In this sugar cane refinery, dust levels were highest in the maintenance department. The type of inhalable dust varied between departments, with more endotoxin per mg inhalable dust in the boiler and mill departments compared to the other departments. For all departments in the refinery, endotoxin and mould levels were very low compared to other agricultural sectors, even when compared to indoor levels. ${ }^{10}$ Mould samples were all below $10^{5}$ spores $/ \mathrm{m}^{3}$, a concentration at which respiratory symptoms, airway inflammation and lung function impairment have been reported. ${ }^{13}$

These low levels can possibly be explained by the time of sampling. We took samples during the harvesting season, when the bagasse that is produced is directly used as an energy source for the rest of the factory. The bagasse is either not stored at all or only stored for a short time. We did not take measurements when the refinery was being started up, when bagasse from last year's harvest was being used. The short storage time and possibly drying of the bagasse prevents proliferation of actinomycetes and fungi. Also, the relative humidity was low (49\% on average) in the months when exposure sampling was performed (February-March). Finally, during the study we learned that a bactericide was used in the process water in the mills to reduce bacterial growth.
A main limitation of this study was its small sample size, possibly causing fluctuations in percentages leading to confusing results, such as the non-significant $(p=0.62)$ decrease in rhinitis prevalence among the other dust group workers during the harvesting season compared to the non-harvesting season (figure 2). Also, for the comparisons between seasons, the reference group consisted only of 15 workers. Nevertheless, models were all stable after adjustment. This study is relevant as it is the first to compare workers' ventilatory lung functions, respiratory symptoms and eye problems between seasons and between exposure groups. ${ }^{15} 16$ Another limitation was the high loss to follow-up (26\%). One worker had an accident and stopped working. The other workers were still working in the company, but due to logistical problems could not be re-assessed. Logistical problems were more frequent among the maintenance workers, grouped in the other dust group, since they worked further away from the nursery department where assessments were performed. However, workers who were lost to follow-up were not statistically significantly different from the rest in terms of reported symptoms or lung function test results during the first visit. Thus, selection bias did not seem to play a role in the present study, as the loss to follow-up was non-specific. Another limitation is that we did not ask about other symptoms related to bagassosis, such as fatigue, weight of loss, fever and chills.

The lung functions differences between exposure groups before the harvesting season are unlikely to be due to bagasse exposure (1) because increased exposure was not associated with an increased effect (the bagasse-exposed group differed less from the reference group than did the group of workers exposed to other dust) and (2) because ventilatory lung functions were 
similar between seasons and did not decrease during the harvesting season.

In contrast to an Australian study, ${ }^{15}$ our results suggest bagasse exposure may cause short- and long-term respiratory effects as bagasse-exposed workers more frequently reported wheeze and $\mathrm{SOB}$ during the harvesting season than before the season. Workers in the other dust group also reported more wheeze problems during the harvesting season but not more SOB. Long-term exposure might be associated with symptoms, as workers who had worked more years in the company more often reported wheeze and SOB during the 12 months before the harvesting season started. The reported symptoms are likely caused by an irritating effect of the bagasse fibres in the respiratory tract ${ }^{53}$ and not an allergic effect, because the endotoxin and mould levels measured in this study were very low. The atopic status of the workers did not change during the harvesting season, and neither did their IgE levels. Exposure to ashes while cleaning the boilers or exposure to the bactericide might have affected these workers as well, ${ }^{30} 31$ but only a few workers $(n=6)$ carried out these activities. Welding fumes, gasoil and other chemicals used while repairing pieces and vehicles might have contributed to the respiratory problems of workers from the other dust group, in particular during the maintenance season, and should be addressed in a future study. ${ }^{30} 32$

In the present study we found that during the harvesting season, reported wheeze and SOB increased, but no differences in lung function parameters were observed. Although several studies have found that lung diseases that cause wheezing are associated with impaired lung function, ${ }^{33}$ others have found associations between exposure and respiratory symptoms but not with ventilatory lung function parameters $\left(\mathrm{FEV}_{1}\right.$ and FVC). ${ }^{31} 34$ In fact, some studies suggest that for the early detection of subclinical respiratory effects, a physiological parameter such as arterial oxygen desaturation during exercise would be a more sensitive indicator. ${ }^{35}$

During the harvesting season, the number of self-reported rhinitis cases increased significantly in workers from the bagasse group. Since rhinitis was not correlated to atopy or total IgE levels, it is unlikely that it was caused by an allergic reaction. Again, the irritating effects of the bagasse might explain the increase which is in accordance with results obtained in other studies on organic dust exposure. ${ }^{5}$ Finally, significant differences were found for eye problems between seasons and groups. These results suggest a short-term effect as well, probably due to bagasse exposure within the bagasse group and to environmental dust and welding fumes in the other dust group. ${ }^{21}$

Levels of total IgE were very high compared to European populations, ${ }^{36}$ but it is known that levels can vary according to genetic and environmental factors (ie, helminth infections, nutritional status, lifestyle, ethnic group and socioeconomic factors). ${ }^{37}$ We do not have an explanation for the fact that we found higher IgE levels in Costa Rican than Nicaraguan workers. Maybe some of the factors mentioned above could explain these differences, but it was beyond the scope of this study to analyse them in detail. As far as we know, bagasse exposure has not been associated with atopy. In our study, atopy status or levels of total IgE within the bagasse group were similar before and during the harvesting season. Exposure to bagasse did not seem to explain the high IgE levels among this population.

\section{CONCLUSIONS}

In this sugar cane refinery, the differences in workers' ventilatory lung function before the harvesting season are unlikely to be explained by bagasse exposure. The short- and long-term symptoms (wheeze, SOB, eye problems and rhinitis) reported by workers in this study, in particular during the harvesting season, are more likely caused by an irritating action of inhalable dust (bagasse or other compounds) than microbiological agents. We recommend reducing workers' exposure to bagasse dust by enclosing the production process.

Acknowledgements The authors would like to thank Marcos Morales and Carlos Arguedas, the nurse and the physician in the company, for their support and collaboration, Jesús Delgado, the company occupational hygienist, and the company for giving us the opportunity to carry out this study. Thanks to María Jesús Arias, Karla Solano, Clemens Rupert, Jack Spithoven, Isabella Oosting and Mischa Zengeni for their help and advice on sampling materials and methods, and colleagues in the Central American Institute for Studies on Toxic Substances, Universidad Nacional (IRET-UNA) for their help during the fieldwork. We are grateful to the workers for their participation.

Funding This project was funded by the Program on Work and Health in Central America (SALTRA), Central American Institute for Studies on Toxic Substances (IRET), Universidad Nacional de Costa Rica (UNA), Heredia, Costa Rica; the Institute for Risk Assessment Sciences (IRAS), Utrecht University, The Netherlands; and the Department of Chemical and Biological Work Environment, National Institute of Occupational Health (STAMI), Oslo, Norway.

\section{Competing interests None.}

Ethics approval The Scientific Ethical Committee, Universidad Nacional, Heredia, Costa Rica approved this study (CEC-UNA-021-2008).

Contributors All authors contributed to all stages of the study (design, data analysis and writing).

Provenance and peer review Not commissioned; externally peer reviewed.

\section{REFERENCES}

1. FAO. Acuerdo sobre la Agricultura de la OMC. La Experiencia de su ejecución Estudios de casos de países en desarrollo. Roma: Organización de las Naciones Unidas para la agricultura y la alimentación, 2004.

2. Barquero M. Alza En Azúcar Devuelve Fe A Miles De Productores. San José, Costa Rica: La Nación, 2006.

3. El Batabi M. Health of Workers in Agriculture. Regional Publications, Eastern Mediterranean Series 25. El Cairo: WHO, 2003.

4. Spaan S, Wouters IM, Oosting I, et al. Exposure to inhalable dust and endotoxins in agricultural industries. J Environ Monit 2006;8:63-72

5. Douwes J, Thorne P, Pearce N, et al. Bioaerosol health effects and exposure assessment: progress and prospects. Ann Occup Hyg 2003;47:187-200.

6. Heederik D, Wouters IM. Endotoxin exposure and health effects: reevaluating the evidence and new research initiatives. Gefahrst Reinhalt L 2007;67:357-60.

7. Smit LA, Heederik D, Doekes G, et al. Exposure-response analysis of allergy and respiratory symptoms in endotoxin-exposed adults. Eur Respir J 2008;31:1241-8.

8. Phoolchund HN. Aspects of occupational health in the sugar cane industry. J Soc Occup Med 1991;41:133-6.

9. Hearn CE, Holford-Strevens V. Immunological aspects of bagassosis. Br J Ind Med 1968;25:283-92

10. Braun-Fahrlander $\mathbf{C}$, Riedler J, Herz U, et al. Environmental exposure to endotoxin and its relation to asthma in school-age children. N Engl J Med 2002;347:869-77.

11. Portengen $L$, Preller $L$, Tielen $M$, et al. Endotoxin exposure and atopic sensitization in adult pig farmers. J Allergy Clin Immunol 2005;115:797-802.

12. Eduard W, Douwes J, Omenaas E, et al. Do farming exposures cause or prevent asthma? Results from a study of adult Norwergian farmers. Thorax 2004;59:381-6.

13. Eduard W. Fungal spores: a critical review of the toxicological and epidemiologica evidence as a basis for occupational exposure limit setting. Crit Rev Toxicol 2009;39:799-864.

14. Khan ZU, Gangwar M, Gaur SN, et al. Thermophilic actinomycetes in cane sugar mills: an aeromicrobiologic and seroepidemiologic study. Antonie Van Leeuwenhoek 1995;67:339-44.

15. Dawson MW, Scott JG, Cox LM. The medical and epidemiologic effects on workers of the levels of airborne Thermoactinomyces Spp. spores present in Australian raw sugar mills. Am Ind Hyg Assoc J 1996;57:1002-12.

16. Hearn CE. Bagassosis: an epidemiological, environmental, and clinical survey. $\mathrm{Br} \mathrm{J}$ Ind Med 1968;25:267-82

17. Romeo L, Molle K, Zanoni G, et al. Respiratory health effects and immunological response to Thermoactinomyces among sugar cane workers in Nicaragua. Int $J$ Occup Environ Health 2009;15:249-54.

18. Zaidi SH, Bhattacherjee JW, Dogra RK, et al. Experimental bagassosis: role of infection. Environ Res 1983;31:279-86.

19. Buechner HA, Prevatt AL, Thompson J, et al. Bagassosis; a review, with further historical data, studies of pulmonary function, and results of adrenal steroid therapy. Am J Med 1958;25:234-47 
20. Weill $\mathbf{H}$, Buechner $\mathbf{H}$, Gonzalez E. Bagassosis. A study of pulmonary function in 20 cases. Ant Int Med 1966;64:737-47.

21. Peate WF. Work-related eye injuries and illnesses. Am Fam Physician 2007:75:1017-22.

22. Douwes J, Versloot P, Hollander A, et al. Influence of various dust sampling and extraction methods on the measurement of airborne endotoxin. Appl Environ Microbiol 1995;61:1793-69.

23. ECRHS. ECRHS Appendix B 1 Main Questionnaire. http://www.ecrhs.org

24. Miller MR, Hankinson J, Brusasco V, et al. Standardisation of spirometry. Eur Respir J 2005;26:319-38.

25. Hankinson JL, Odencrantz JR, Fedan KB. Spirometric reference values from a sample of the general U.S. population. Am J Respir Crit Care Med 1999;159:179-87.

26. Doekes G, Douwes J, Wouters I, et al. Enzyme immunoassays for total and allergen specific lgE in population studies. Occup Environ Med 1996;53:63-70.

27. Lubin J, Colt J, Camann D, et al. Epidemiologic evaluation of measurement data in the presence of detection limits. Environ Health Perspect 2004;112 1691-6.

28. Kromhout $\mathbf{H}$, Heederik D. Occupational epidemiology in the rubber industry: implications of exposure variability. Am J Ind Med 1995;27:171-85.

29. Gehring U, Heinrich J, Hoek G, et al. Bacteria and mould components in house dust and children's allergic sensitisation. Eur Respir J 2007;29:1144-53.
30. Mapp CE, Boschetto P, Maestrelli P, et al. Occupational asthma. Am J Respir Crit Care Med 2005;172:280-305.

31. Fieten KB, Kromhout $\mathrm{H}$, Heederik D, et al. Pesticide exposure and respiratory health of indigenous women in Costa Rica. Am J Epidemiol 2009;169:1500-6.

32. Ozdemir $\mathbf{0}$, Numanoğlu N, Gönüllü U, et al. Chronic effects of welding exposure on pulmonary function tests and respiratory symptoms. Occup Environ Med 1995:52:800-3.

33. Sunyer J, Basagana $X$, Roca J, et al. Relations between respiratory symptoms and spirometric values in young adults: the European community respiratory health study. Respir Med 2004;98:1025-33.

34. Voll-Aanerud M, Eagan TM, Wentzel-Larsen T, et al. Respiratory symptoms, COPD severity, and health related quality of life in a general population sample. Respir Med 2008;102:399-406.

35. Dalvie MA, White $N$, Raine $R$, et al. Long-term respiratory health effects of the herbicide, paraquat, among workers in the Western Cape. Occup Environ Med 1999;56:391-6.

36. Carosso A, Bugiani M, Migliore $\mathrm{E}$, et al. Reference values of total serum IgE and their significance in the diagnosis of allergy in young European adults. Int Arch Allergy Immunol 2007;142:230-8.

37. Lomonte B, Salas P, Quesada F. Determinación inmunoenzimática de los niveles de inmunoglobulina en niños asmáticos de la meseta central de Costa Rica. Rev Costaricense Cien Med 1988;9:57-64.

\section{DIFFERENTIAL DIAGNOSIS}

\section{Trustworthy guidance on your iPhone}
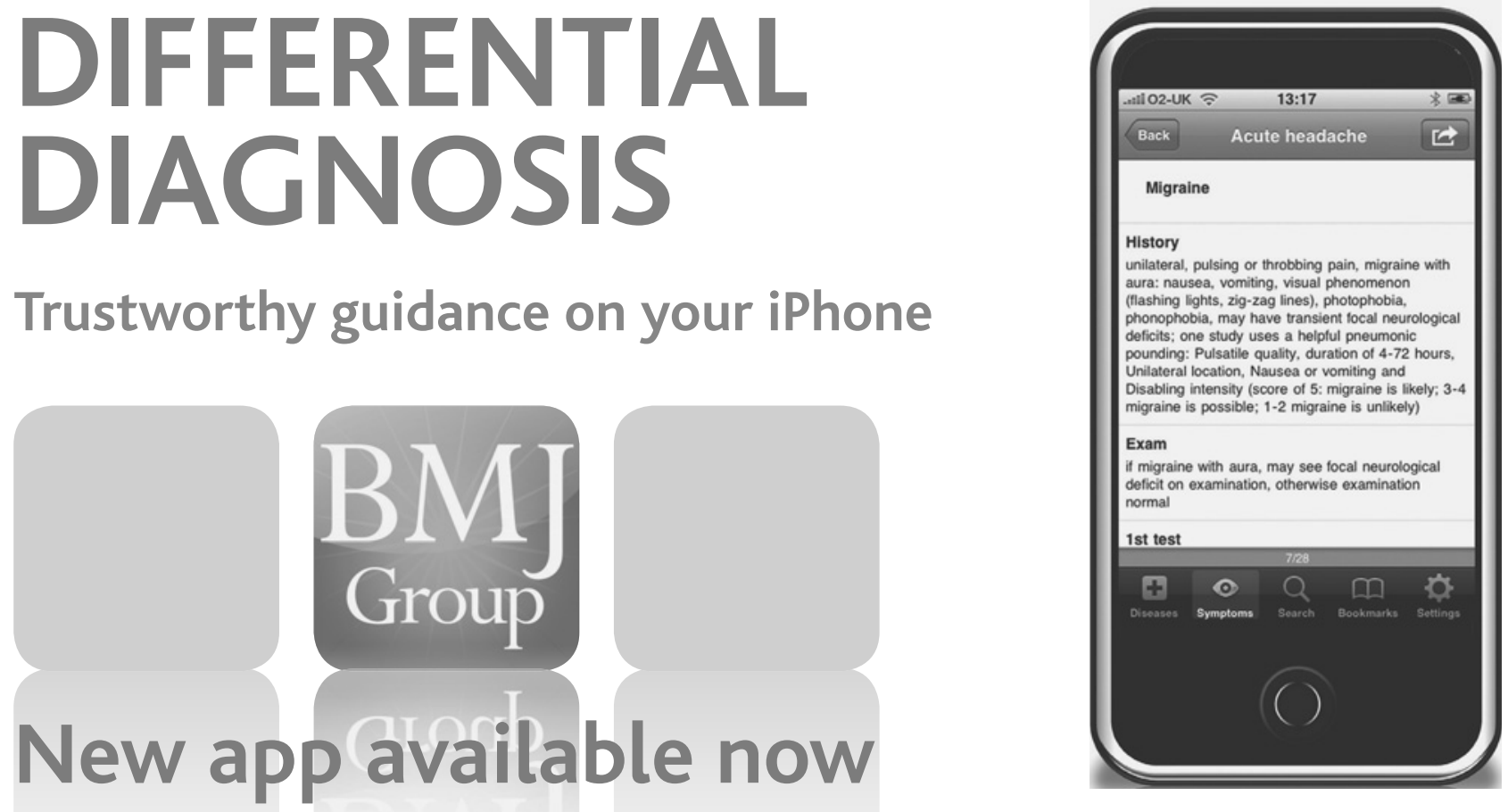

Find out more at bestpractice.bmj.com/differentials 

bagasse-exposed sugar cane workers in Costa Rica

Mireia Gascon, Hans Kromhout, Dick Heederik, et al.

Occup Environ Med 2012 69: 331-338 originally published online January 22, 2012

doi: 10.1136/oemed-2011-100029

Updated information and services can be found at:

http://oem.bmj.com/content/69/5/331.full.html

\section{These include:}

References This article cites 33 articles, 11 of which can be accessed free at: http://oem.bmj.com/content/69/5/331.full.html\#ref-list-1

Email alerting

Receive free email alerts when new articles cite this article. Sign up in service the box at the top right corner of the online article.

Notes

To request permissions go to:

http://group.bmj.com/group/rights-licensing/permissions

To order reprints go to:

http://journals.bmj.com/cgi/reprintform

To subscribe to BMJ go to:

http://group.bmj.com/subscribe/ 